\title{
Integrated risk assessment of multi-hazards in China
}

\author{
Yang $\mathrm{Zhou}^{1} \cdot$ Yansui Liu' ${ }^{1}$ Wenxiang $\mathrm{Wu}^{1} \cdot \operatorname{Ning} \mathrm{Li}^{2,3,4}$
}

Received: 28 October 2014/Accepted: 14 March 2015/Published online: 28 March 2015

(C) Springer Science+Business Media Dordrecht 2015

\begin{abstract}
Maps of population exposure, vulnerability and risk to natural hazards are useful tools for designing and implementing disaster risk mitigation programs in China. The ranking of provinces by relative risk to natural hazards would provide a metric for prioritizing risk management strategies. Using provinces as our study unit, from the perspectives of hazard exposure, susceptibility, coping capacity and adaptive capacity, this study first constructed China's disaster risk index for five types of major natural hazards: earthquakes, floods, droughts, low temperatures/snow and gale/hail. Then, the relative risk level at the provincial scale in China was assessed. Finally, the hotspots with the highest hazard exposure, vulnerability and risk were identified. The results showed that high exposure was a significant risk driver in China, whereas high vulnerability, especially social vulnerability, amplified the risk levels. Similar to the population exposure to disasters, the relative risk levels in the southwestern, central and northeastern regions of China were significantly higher than those in the eastern, northern and western regions. The highrisk regions or hotspots of multi-hazards were concentrated in southern China (less-developed regions), while the low-risk regions were mainly distributed in the eastern coastal areas (well-developed regions). Furthermore, a nonlinear relationship existed between the disaster risk level and poverty incidence as well as per capita GDP, demonstrating that
\end{abstract}

Ning Li

ningli@bnu.edu.cn

Yang Zhou

yzhou@mail.bnu.edu.cn

1 Institute of Geographical Sciences and Natural Resources Research, Chinese Academy of Sciences, Beijing 100101, China

2 State Key Laboratory of Earth Surface Processes and Resource Ecology, Beijing Normal University, Beijing 100875, China

3 Key Laboratory of Environmental Change and Natural Disaster, MOE, Beijing Normal University, Beijing 100875, China

4 Academy of Disaster Reduction and Emergency Management, Ministry of Civil Affairs, Ministry of Education, Beijing Normal University, Beijing 100875, China 
disaster losses in middle-income areas are likely to increase if economic policies are not modified to account for the rising disaster risk. These findings further indicated that research on disaster risk should focus not only on hazards and exposure but also on the vulnerability to natural disasters. Thus, reducing vulnerability and population exposure to natural hazards would be an effective measure in mitigating the disaster risk at hotspots in China.

Keywords Natural disasters · Multi-hazard risk assessment - China's disaster risk index (CDRI) - Vulnerability

\section{Introduction}

Disaster risk signifies the possibility of adverse effects in the future, and it derives from the interaction of social and environmental processes and from the combination of physical hazards and the vulnerabilities of exposed elements (IPCC 2012). Risk is generally associated with several definitions and multiple approaches (Adger 2006). In the disaster risk field, risk is generally defined as a function of hazard probability and vulnerability; the latter results from a combination of susceptibility and coping and adaptive capacities (UN/ ISDR 2004; Wisner et al. 2004).

Disaster risk assessment could also help to develop and implement the multi-hazard risk management strategies (Dilley et al. 2005). With the increasing number of disasters and its losses, disaster risk assessment has long been a major concern in the field of natural disaster and sustainability science. Identifying the risk factors could provide opportunities to shift the emphasis from reliance on relief and reconstruction following disasters toward prevention of losses and preparedness to reduce recovery time (Dilley et al. 2005; Birkmann 2007). Various attempts have been made to measure risk and vulnerability across different spatial scales over the past decades (Dilley et al. 2005; UNDP 2004; Cutter and Finch 2008; Schmidtlein et al. 2008; Cardona 2011). Traditionally, risk assessments aim to determine the likelihood of specific losses and damages to the population, economy, supporting environment and institutional structures (UNESCO-IOC 2009), which in turn has a particular focus on exposure but also from an engineering approach (Fuchs et al. 2013). However, risk assessment has recently shifted from pure quantification of probability of losses and damages of elements at risk due to a hazard (purely related to exposure and susceptibility considerations of the elements at risk) toward the explicit consideration of coping and adaptive capacities and deficiencies in the preparedness of society (Strunz et al. 2011). Some global and regional approaches, such as the disaster risk index (DRI) (UNDP 2004) and the Natural Disaster Risk Hotspots project (NDRHP) (Dilley et al. 2005), have been established to measure the relative levels of risk at the national level by considering historical annual mortality rates, economic loss rates and exposed populations to different hazards. Specifically, the United Nations Development Programme in 2004 introduced the DRI to assess the risk classes of the main natural hazards (including droughts, floods, cyclones and earthquakes) at the national level based on the publicly available Emergency Event Database (EM-DAT). The DRI is a quantitative measure that permits a comparison of disaster risk between countries exposed to selected hazards and an exploration of the correlation of a country's development status and its vulnerability to natural disasters (Birkmann 2007; Peduzzi et al. 2009); see also Cutter and Finch (2008) 
for an application in the USA. Countries suffering higher losses of lives than other countries equally exposed have a higher relative vulnerability (Dilley et al. 2005). In the global spatial distribution map of DRI classes $(0=$ no mortality risk to $7=$ highest mortality risk), China belongs to the sixth class, which comprises areas of relatively higher risk (Peduzzi et al. 2009). Due to the lower spatial resolution (at the national scale) of the hazard and exposure, as well as the vulnerability parameters, the DRI failed to reveal the relative disaster risk levels within countries. Therefore, Peduzzi et al. (2009) suggested that large countries with significant discrepancies, such as China, should have more disaggregated risk rates for policy-making and the implementation of disaster prevention and mitigation.

The NDRHP, one of the most influential disaster risk assessments, was conducted primarily by Columbia University in cooperation with the World Bank and other institutes (Dilley et al. 2005). The aim of the NDRHP was to perform a global assessment of the risk of mortality and economic losses for six major natural hazards: droughts, floods, windstorms, earthquakes, landslides and volcanoes. The NDRHP study assessed the global relative risks of mortality and economic losses associated with each hazard and all hazards combined using proxies based on gridded population density and GDP per unit area for $2000(5 \mathrm{~km} \times 5 \mathrm{~km}$ cell $)$. Like the DRI, the NDRHP used the EM-DAT database for the calculations and was thus limited to large events. This challenge was also addressed recently for Europe and the Russian Federation by Fuchs et al. (2013). The resolution of the global analysis is relatively coarse, however, and the global dataset inadequately captured important factors affecting local risk levels (Arnold et al. 2006). In the NDRHP study, the eastern and southeastern coastal regions of China were identified as cyclone and flood disaster risk hotspots in terms of mortalities and economic losses, and the northern region was identified as a drought risk hotspot. Regarding mortality risk, the eastern and central areas of China were dominated by hydrological disaster hotspots; regarding economic loss risks, the central and southeastern regions were dominated by hydrological disaster hotspots; the northern and northeastern parts were dominated by hydrological and drought disaster hotspots (Dilley et al. 2005). However, as the study omitted more precise estimates of physical fragilities and social vulnerabilities where they existed, it was difficult to accurately estimate the mortality and economic losses from the empirical loss rate analysis at a local scale (Lerner-Lam 2007). The NDRHP and similar recent studies have pointed to the specific need for more research, standardized data acquisition and more highly resolved regional and sub-national analyses (Arnold et al. 2006; Alliance Development Works 2012).

Recently, the United Nations University and the Institute for Environment and Human Security, in the World Risk Report (WRR), estimated that 173 states worldwide are exposed to earthquakes, floods, droughts, cyclones and sea level rise based on the world risk index (WRI) (Alliance Development Works 2012). The WRI is calculated by combining the four individually calculated components of exposure, susceptibility, lack of coping capacities and lack of adaptive capacities. In the WRR, the levels of susceptibility, exposure, vulnerability, lack of coping and adaptive capabilities, and risk were divided into five classes: very low, low, medium, high and very high. Because the WRI applied a wider range of vulnerability indicators that focused on attributes of sensitivity, coping and adaptive capacities, rather than exposure dimensions and past impacts from disasters, it could more fully identify the multi-hazard hotspots globally than other global risk indices. According to the WRR, China had a medium level of exposure, vulnerability, and disaster risk, and it ranked 78th out of 173 countries worldwide in terms of risk level. The susceptibility, lack of adaptive ability and lack of coping capability regarding natural hazards 
in China were at a medium level (Alliance Development Works 2012). The WRR stressed that China experienced different regional disaster risks due to the varied geographical areas. It is thus difficult to compare risks across provinces without a systematic disaster risk assessment and the identification of underlying risk factors. Without geographical comparisons, it is also difficult to prioritize the geographical focus of risk reduction strategies or position them within the broader sustainable development and poverty reduction goals (Linnerooth-Bayer et al. 2007). The higher resolution of the local risk index made it possible to representing the exposure and vulnerability on a smaller scale. Thus, the multihazard risk assessment on the local level still deserves further investigation.

China's vast territory, varied climate region, complex geographical environment and fragile ecological condition make it one of the countries to suffer from frequent disasters. The natural hazards in China are characterized with a wide distribution, occurring at a high frequency and often causing huge losses. The natural hazards in China have had a farreaching impact on the sustainable development of China's economy and society, thus being a particular domestic and international concern (Zhou et al. 2014a). On average, China's natural hazards from 1990 to 2011 affected about 400 million people per year over, claimed the lives of more than 8,000 victims and caused direct economic losses exceeding 100 billion RMB (Zhou et al. 2013). Although a large number of studies have been conducted on disaster-causing factors and spatiotemporal patterns of various natural hazards, the relative risk levels of multi-hazards from the perspectives of hazards, exposure and vulnerability are still poorly understood (Wang et al. 1994, 2006). Fortunately, in a recent study, Shi (2011) assessed the risk level of integrated natural disasters at the county level and concluded that the risk level of East China was higher than that in Central China; also, the risk in the central region was higher than that in the western region. Due to the higher resolution data compared with previous studies, Shi's findings provided comprehensive and in-depth insights into the relative risk levels of integrated natural disasters; the findings were extremely useful for guiding the actions in disaster prevention and mitigation in China. However, due to the limitation of data, Shi's study (2011) failed to fully take into account the susceptibility, coping ability and adaptive capacity regarding natural hazards. Multi-hazard risk analyses of considering risk factors (i.e., hazards, susceptibility, coping ability, adaptive capacity) are valuable to get an overview on the overall risk profile of a region and have a great significance for designing and implementing effective disaster risk mitigation countermeasures (Bell and Glade 2004; Birkmann et al. 2011a; Kappes et al. 2012). The key aim of this study is to assess the risk levels by combining both the frequency of the five major natural hazards (i.e., earthquakes, floods, droughts, low temperatures/snow and gale/hail) and the vulnerability of the society or element at risk exposed at the provincial level in China and to identify the possible mechanisms associated with high-risk regions or hotspots.

\section{Theoretical frameworks, methods and data}

In the present study, risk is also defined as the interaction between a hazard event and the exposed element or society (UN/ISDR 2004; Wisner et al. 2004; Birkmann 2006; Birkmann et al. 2011a). Following the theoretical framework of the WRR, an index was constructed for 31 provinces (municipalities and autonomous regions) in China to examine the regional differences in terms of exposure, susceptibility, coping and adaptive capacities and risk level. China's disaster risk index (CDRI) was thus measured on the basis of four 
components: exposure, susceptibility, coping capacity and adaptive capacity. The concept of vulnerability is used by various disciplines, and current approaches in vulnerability research are driven by a divide between social scientists and natural scientist (Fuchs et al. 2012). Social scientists view vulnerability as representing the set of socioeconomic factors that determine people's ability to cope with or changes (Wisner et al. 2004; Birkmann 2006; IPCC 2012) or call it social vulnerability (Cutter and Finch 2008; Zhou et al. 2014a), whereas natural scientists focus on vulnerability in terms of the likelihood of occurrence of a specific event and associated impacts on the built environment, also known as physical vulnerability (Papathoma-Kohle et al. 2011). Birkmann et al. (2013) concluded the dimensions of vulnerability from social, economic, physical, cultural, environmental and institutional aspects. The institutional dimension include potential for damage to governance systems, organizational form and function as well as guiding formal/legal rules (Birkmann et al. 2013). In this study, vulnerability refers to social, physical, economic and environmental factors that make people or systems susceptible to the impacts of natural hazards and adverse consequences of shocks (Wisner et al. 2004; Birkmann 2006; Birkmann et al. 2011a). The susceptibility, lack of coping capacity and the lack of adaptive capacity describe the societal elements of the risks; combined, they yield the vulnerability index. The vulnerability index multiplied by the exposure index produces the risk. Thus, the CDRI can be calculated by the following equations:

$$
\begin{aligned}
\mathrm{CDRI} & =\text { Exposure } \times \text { Vulnerability } \\
& =\text { Exposure } \times[\text { Susceptibility }+(1-\text { Coping capacity })+(1-\text { Adaptive capacity })]
\end{aligned}
$$

where Exposure refers to entities (population, built-up area, infrastructure component, environmental areas) being exposed to the effects of one or more natural hazards. This study focused on two different types of natural hazards: sudden-onset hazards, such as floods, earthquakes and gale/hail, and gradually or slowly occurring processes, such as drought and low temperatures/snow. The frequencies of the five types of natural hazards in China before 2008 are not available. Therefore, this study is only concerned with the annual physical exposure of the population to earthquakes, droughts, floods, low temperatures/snow and gale/hail from 2008 to $2010 .{ }^{1}$ During 2008-2010, 29 of the 31 provinces experienced floods, gale/hail and low temperatures/snow, and 24 and 25 of the 31 provinces suffered from earthquakes and droughts, respectively (Fig. 1). The number of hazards is also taken into account and is obtained from a publicly accessible database (http://zaiqing.casm.ac.cn/). The population exposure in this study was associated with the annual average number of individuals who are affected by hazard events. All exposed population per natural hazard was summed to estimate the exposure index that represents the share of the population exposed in each province. The physical exposure to hazards may be defined as follows:

$$
\text { Exposure }_{i}=\sum \frac{\text { Pop }_{i}}{N \times Y_{n}}
$$

where Exposure $_{i}$ is the annual average physical exposure for the " $i$ " hazard in each province (person/year), $\mathrm{Pop}_{i}$ is the total affected population for each hazard event " $i$ " (person- event), $N$ is the annual number of a disaster type (event) and $Y_{n}$ is the length of time [year].

1 The five types of natural hazards accounted for $91.75,97.22$ and $90.51 \%$ of the affected population, death toll and direct economic losses, respectively, in China for the period of 2002-2011 (MCAC 2012). 


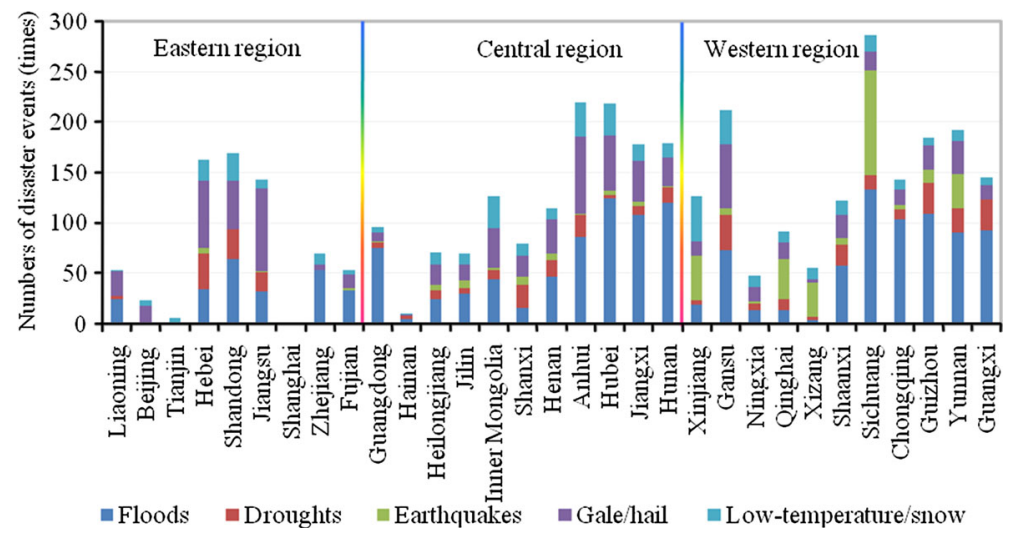

Fig. 1 Number of disasters for different provinces in China from 2008 to 2010

Susceptibility generally refers to the likelihood of harm, loss and disruption in an extreme event triggered by a natural hazard. Public infrastructure, health status, poverty and dependencies, and economic capacity and income distribution were chosen to represent susceptibility. Figure 2 and Table 1 show the four sub-categories, the seven selected indicators and the corresponding weights. To compare the world risk index, the weights of four sub-category metrics representing susceptibility in the present study were based on a weighting scheme from the WRR, which was obtained from an expert evaluation.

Coping capacity refers to the ability of people, organizations and systems to address, manage and overcome adverse conditions using available skills, resources and opportunities (IPCC 2012). It comprise various abilities of societies and exposed elements to minimize negative impacts of natural hazards through direct action and the resources available, and it also encompasses measures and abilities that are immediately available to reduce harm and damages in the occurrence of an event (Alliance Development Works 2012). Three sub-category indicators, i.e., government and authorities, medical services and economic coverage, were chosen to represent the coping capacities, which could also be described as institutional and economic vulnerabilities (Raschky 2008; Birkmann et al. 2013). To calculate the risk index, the opposite value, i.e., the lack of coping capacities, was used; the value is calculated as 1 minus the coping capacities.

Adaptive capacity refers to the ability to prepare for stresses and changes in advance or adjust and respond to the effects caused by the stress (Smit et al. 2001; Adger et al. 2007; IPCC 2012). Coping is typically used to refer to ex post actions, while adaptation is normally associated with ex ante actions (IPCC 2012). Coping aims to maintain the system and its functions in the face of adverse shocks, while adaptation involves in changes and requires reorganization processes (Birkmann 2011b). Enhancement of adaptability is a necessary condition for reducing vulnerability (Smit et al. 2001). In this study, four subcategory proxy variables that describe the capacities for long-term adaptation and change within a society were chosen: education and research, gender equity, environmental status/ ecosystem protection and financial investments. Figure 2 and Table 1 show these four subcategory variables and the sixteen selected indicators, as well as their corresponding weights. Similar to the coping capacities, the lack of adaptive capacities was included in the CDRI. 


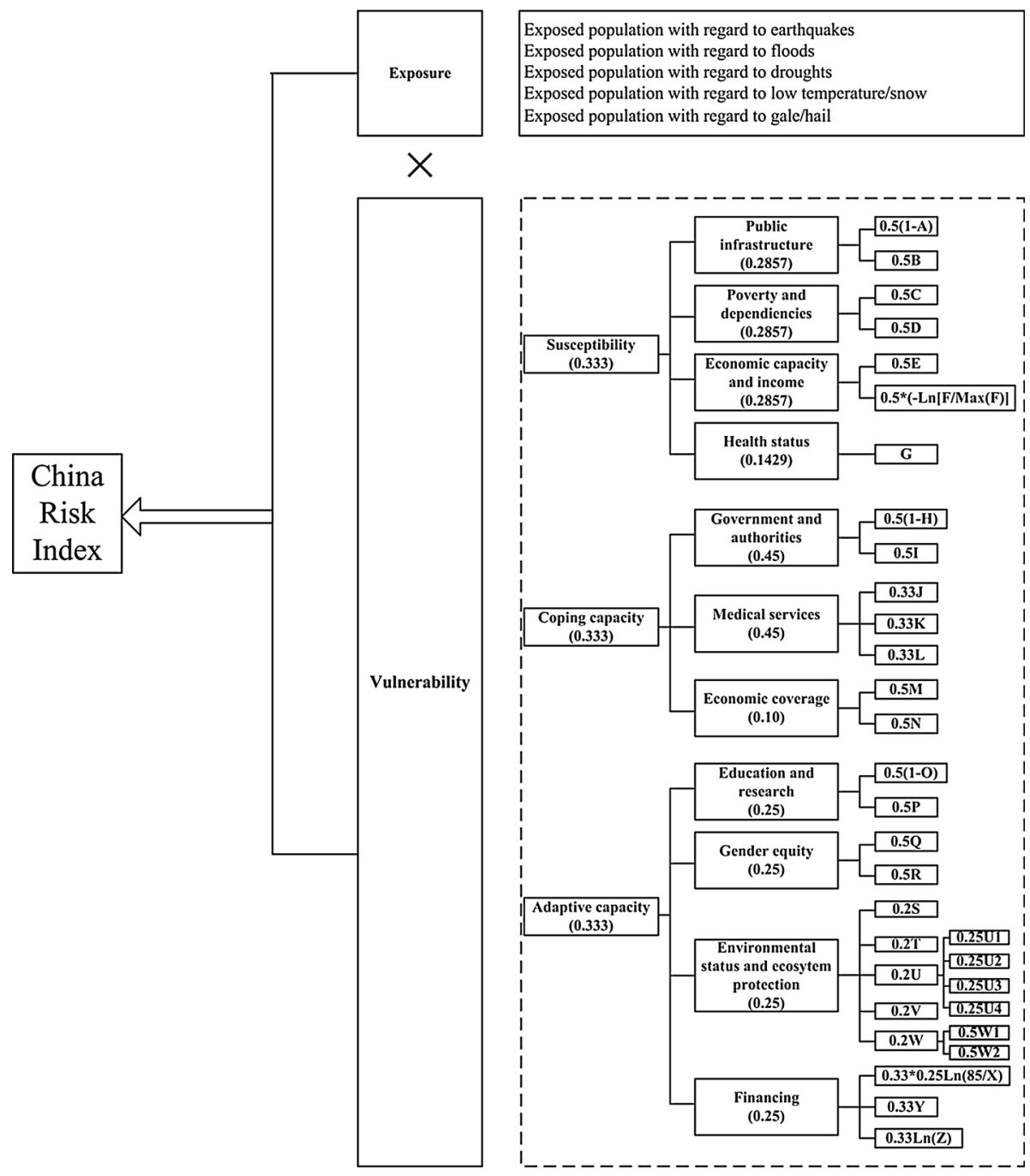

Fig. 2 Calculation of China's disaster risk index (modified from Alliance Development Works 2012). Note The letters from $A$ to $Z$ represent the sub-indicators in Table 1, the figures in parentheses are the weights for each indicator, and the figures before the letters are for the calculation of the weighted average

Table 1 lists the 35 proxy indicators and the sources for measuring the CDRI in 31 provinces. Some of the indicators were obtained from official publications, such as the China Statistical Yearbook and Yearbook of China's Insurance, and some were available from peer-reviewed papers (see Table 1). All indicators are statistically and analytically accurate, comparable and as simple as possible to interpret. Many of the indicators composing the CDRI ranged from 0 to 1 or 0 to 100 . When dealing with data ranges larger than 100 , standardization was used for transforming values to between 0 and 1 . This transformation was only used if the measurement units were not proportional to the population. Special cases of logarithmic transformation were used for GDP, life expectancy at birth and expenditure on health. Figure 2 exhibits the modular structure of the indicators of 
Table 1 Indicators for the CDRI at the provincial scale

\begin{tabular}{|c|c|c|}
\hline & Year & Sources \\
\hline \multicolumn{3}{|l|}{ Exposure: exposed population with regard to } \\
\hline $\begin{array}{l}\text { Earthquakes (the affected population and the } \\
\text { number of earthquakes during 2008-2010) }\end{array}$ & 2008-2010 & MCAC (2012), NASMG (2013) \\
\hline $\begin{array}{l}\text { Floods (the affected population and the number of } \\
\text { floods during 2008-2010) }\end{array}$ & 2008-2010 & MCAC (2012), NASMG (2013) \\
\hline $\begin{array}{l}\text { Droughts (the affected population and the number } \\
\text { of droughts during 2008-2010) }\end{array}$ & 2008-2010 & MCAC (2012), NASMG (2013) \\
\hline $\begin{array}{l}\text { Low temperatures/snow (the affected population } \\
\text { and the number of low temperature/snow during } \\
\text { 2008-2010) }\end{array}$ & 2008-2010 & MCAC (2012), NASMG (2013) \\
\hline $\begin{array}{l}\text { Gale/hail (the affected population and the number } \\
\text { of gale/hail during 2008-2010) }\end{array}$ & 2008-2010 & MCAC (2012), NASMG (2013) \\
\hline \multicolumn{3}{|l|}{ Susceptibility (likelihood of suffering harm) } \\
\hline \multicolumn{3}{|l|}{ Public Infrastructure } \\
\hline A: Number of public buses per 10,000 people & 2010 & NBSC (2011) \\
\hline $\begin{array}{l}\text { B: Proportion of households of difficult access to } \\
\text { drinking water }(\%)\end{array}$ & 2010 & SCLGO (2010) \\
\hline \multicolumn{3}{|l|}{ Poverty and dependencies } \\
\hline $\begin{array}{l}\text { C: Dependency ratio ( } \% \text { proportion of under } 15- \\
\text { and above } 65 \text {-year-olds in relation to the } \\
\text { working population) }\end{array}$ & 2010 & NBSC (2011) \\
\hline $\begin{array}{l}\text { D: Incidence of poverty (\% urban and rural } \\
\text { poverty) }\end{array}$ & 2010 & MCAC (2012) \\
\hline \multicolumn{3}{|l|}{ Economic capacity and income } \\
\hline $\begin{array}{l}\text { E: Gross domestic product per capita (RMB/ } \\
\text { person) }\end{array}$ & 2010 & NBSC (2011) \\
\hline F: Gini-index & 2010 & Tian (2012) \\
\hline \multicolumn{3}{|l|}{ Health } \\
\hline $\begin{array}{l}\text { G: Health index (\% life expectancy at birth, infant } \\
\text { mortality rate, number of beds per million } \\
\text { people) }\end{array}$ & 2006-2010 & NSRCRUC (2012) \\
\hline \multicolumn{3}{|l|}{ Coping capacity (to reduce negative consequences) } \\
\hline \multicolumn{3}{|l|}{ Government and authorities } \\
\hline $\begin{array}{l}\text { H: Corruption level (average annual registered } \\
\text { cases on corruption per } 100,000 \text { public } \\
\text { servants) }\end{array}$ & 1998-2010 & SPP (2010), Dong and Torgler (2013) \\
\hline I: Comprehensive development index ${ }^{\mathrm{b}}$ & $2000-2010$ & NBSRI (2011) \\
\hline \multicolumn{3}{|l|}{ Medical services } \\
\hline $\mathrm{J}$ : Number of physicians per 10,000 population & 2010 & MHC (2011) \\
\hline K: Number of hospital beds per 10,000 population & 2010 & MHC (2011) \\
\hline L: Number of health institutions & 2010 & MHC (2011) \\
\hline \multicolumn{3}{|l|}{ Economic coverage } \\
\hline M: Insurance density (except life insurance) & $2006-2010$ & $\mathrm{Li}(2011)$ \\
\hline $\mathrm{N}$ : Insurance penetration (except life insurance) & $2006-2010$ & $\mathrm{Li}(2011)$ \\
\hline \multicolumn{3}{|c|}{ Adaptive capacity (for long-term strategies for societal change) } \\
\hline \multicolumn{3}{|l|}{ Education and research } \\
\hline O: Adult literacy rate $(\%)$ & 2010 & PESDNBS (2011) \\
\hline P: Tertiary gross enrollment ratio $(\%)$ & 2010 & MEC (2011) \\
\hline
\end{tabular}


Table 1 continued

\begin{tabular}{|c|c|c|}
\hline & Year & Sources \\
\hline \multicolumn{3}{|l|}{ Gender equity } \\
\hline $\begin{array}{l}\text { Q: Gender parity in education (\% in primary, } \\
\text { secondary and tertiary educational institutions) }\end{array}$ & $2000-2010$ & PESDNBS (2011) \\
\hline $\begin{array}{l}\text { R: Sex ratio of staff in state organs, the party } \\
\text { intelligence organizations, enterprises and } \\
\text { institutions (female/male) }\end{array}$ & 2010 & $\operatorname{SCO}(2011)$ \\
\hline \multicolumn{3}{|l|}{ Environmental status and ecosystem protection } \\
\hline S: Water resources carrying capacity index $(\%)^{\mathrm{c}}$ & 2008 & Liu et al. (2012) \\
\hline $\begin{array}{l}\text { T: Protection of biodiversity (proportion of natural } \\
\text { reserve area \%) }\end{array}$ & 2008 & NBSC (2011) \\
\hline \multicolumn{3}{|l|}{ U: Agricultural management } \\
\hline U1: Annual total water footprint $\left(10^{8} \mathrm{~m}^{3} / \mathrm{a}\right)^{\mathrm{d}}$ & $1995-2005$ & Ge et al. (2011), Sun et al. (2013) \\
\hline U2: Grain subsidy $\left(10^{8} \mathrm{RMB}\right)$ & 2007 & Wang and Mu (2009) \\
\hline $\begin{array}{l}\text { U3: Pest control (\% ratio of pest control area and } \\
\text { occurrence area) }\end{array}$ & $2005-2010$ & RSIDNBC (2011) \\
\hline U4: Pesticide usage $(1,000 \mathrm{~kg})$ & $2005-2010$ & RSIDNBC (2011) \\
\hline $\begin{array}{l}\text { V: Forest management (annual forest cover rate } \\
\% \text {, total standing forest stock } 10,000 \mathrm{cu} . \mathrm{m})\end{array}$ & 1994-2008 & NBSC (2011) \\
\hline \multicolumn{3}{|l|}{ W: Ecological condition } \\
\hline W1: Ecological Footprint (10,000 gha) & 2010 & Wang et al. (2012a) \\
\hline $\begin{array}{l}\text { W2: Terrestrial ecosystem service value }\left(10^{8}\right. \\
\text { RMB) }\end{array}$ & 2008 & Shi et al. (2012) \\
\hline \multicolumn{3}{|l|}{ Financing } \\
\hline $\mathrm{X}$ : Life expectancy at birth & 2010 & SCO (2011) \\
\hline $\begin{array}{l}\text { Y: Private health expenditure ( } \% \text { in percentage of } \\
\text { total health expenditure) }\end{array}$ & 2010 & $\begin{array}{l}\text { MHC (2011), Wang et al. (2012b), Liu et al. } \\
\text { (2013), Gao et al. (2011), Xiao and Lei } \\
\text { (2012) }\end{array}$ \\
\hline $\begin{array}{l}\text { Z: Government health expenditure (per capita } \\
\text { government expenditure on health) (RMB/per } \\
\text { person) }\end{array}$ & 2010 & $\begin{array}{l}\text { MHC (2011), Wang et al. (2012b), Liu et al. } \\
\text { (2013), Gao et al. (2011), Xiao and Lei } \\
\text { (2012) }\end{array}$ \\
\hline
\end{tabular}

a The incidence of poverty for each province includes urban and rural extreme poor incidences. In China, the urban poverty population is currently defined as those people with annual per capita income of less than 2,733.6 RMB (in 2009 prices), and the rural poor population as those people with annual per capita income of less than 1,076 RMB (in 2007 prices) (MCAC 2012)

b Comprehensive development index (CDI) is an important metric for measuring the comprehensive development level in various regions, and it is composed of five sub-category variables (economic development, people's livelihood improvement, social development, ecological construction and technology innovation) and the forty-five indicators (NBSRI 2011)

c Water resources carrying capacity refers to the maximum ability that water can supply industrial and agricultural production, people's living, ecological and environmental protection under the foreseeable technical, economic and social conditions without the fear of disrupting the ecological system. The water resources carrying capacity index includes four sub-category variables (water resources, social and economic system and ecosystem) and twenty-eight indicators (Liu et al. 2012)

d The water footprint of an individual, community or business is defined as the total volume f freshwater used to produce the goods and services for consumption. In this study, the total water footprint includes the agricultural and livestock, industrial products, water pollution, living and ecological water footprint (Sun et al. 2013) 


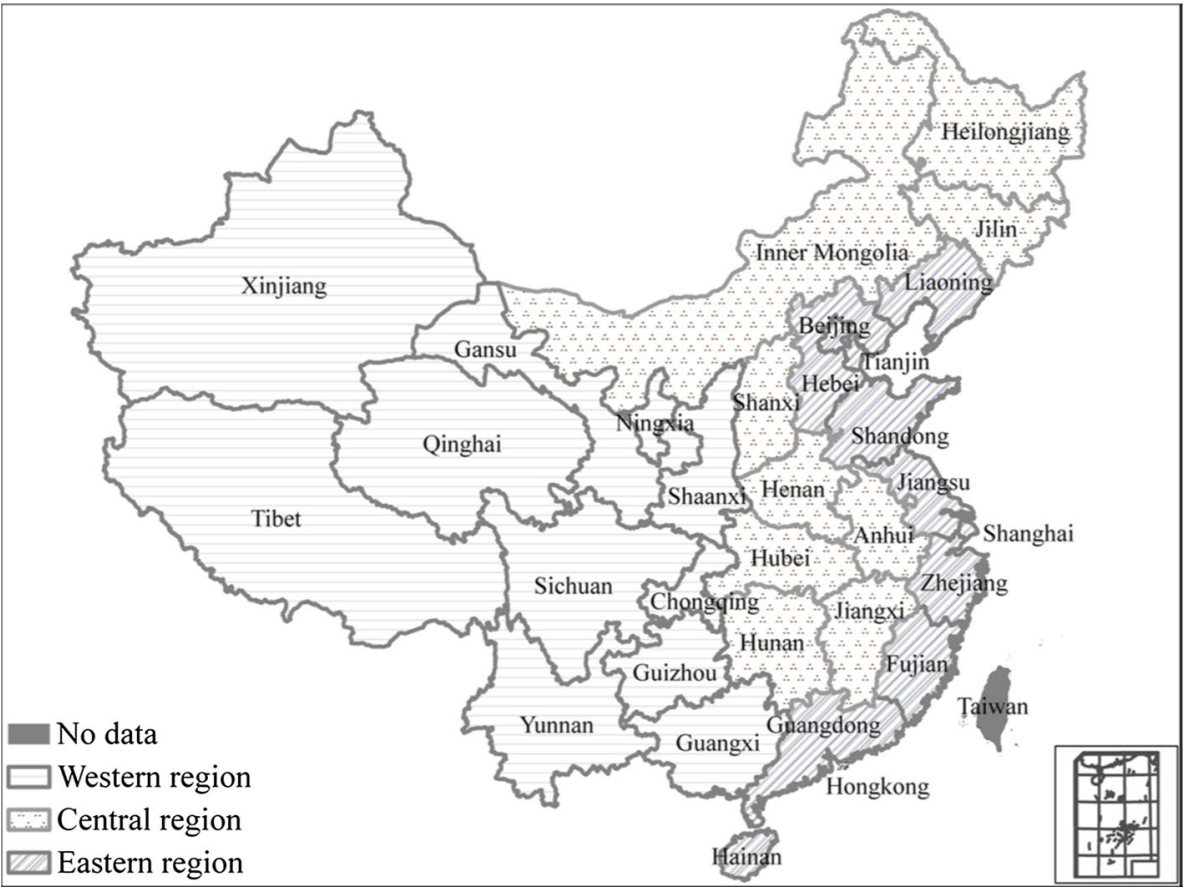

Fig. 3 Eastern, central and western regions of China

exposure, susceptibility, coping capacity and adaptive capacity, as well as their corresponding sub-categories and weights.

Factor analysis was applied to validate the aggregation formula of the CDRI. The results of the factor analysis provide information about the choice of the mathematical aggregation of the four different aggregated indices (exposure, susceptibility, coping and adaptation). The Kaiser-Meyer-Olkin (KMO) measure was commonly used to examine the suitability of the data for factor analysis. The KMO statistic varies between 0 and 1. Kaiser (1974) suggests that values greater than 0.5 are acceptable, values between 0.5 and 0.7 are mediocre, values between 0.7 and 0.8 are good and values between 0.8 and 0.9 are superb. The result of the factor analysis of the used aggregation formula in this study was 0.6 , which means that the choice for the used aggregation formula was reasonable. In addition, for the spatial analysis and cartographic output, the values of the calculated indices were thus separated into five classes using the quantile classification method, which is integrated in the ArcGIS 10.0 software. Based on the calculated indices for exposure, susceptibility, lack of coping capacity, lack of adaptive capacity, vulnerability and risk, we define five classes according to percentile index, i.e., very high ( $\geq 90 \%)$, high (75-90\%), medium $(25-75 \%)$, low $(10-25 \%)$ and very low $(\leq 10 \%)$.

China can generally be divided into eastern, central and western regions according to the level of economic development and geographical location for each province ${ }^{2}$ (Fig. 3).

\footnotetext{
${ }^{2}$ The eastern region of China includes Liaoning, Hebei, Beijing, Tianjin, Shangdong, Jiangsu, Zhejiang, Shanghai, Fujian, Guangdong and Hainan; the western region includes Shannxi, Gansu, Qinghai, Ningxia, Xinjiang, Sichuan, Chongqing, Yunnan, Guizhou, Guangxi and Tibet; and the central region are Shanxi, Jilin, Heilongjiang, Inner Mongolia, Anhui, Jiangxi, Henai, Hubei and Hunan.
} 
Table 2 Indices of exposure, susceptibility, coping and adaptive capacities, and vulnerability and risk for 31 provinces in China

\begin{tabular}{|c|c|c|c|c|c|c|}
\hline Province & Exposure & Susceptibility & Lack of coping capacities & Lack of adaptive capacities & Vulnerability & Risk \\
\hline Guizhou & 71.509 & 84.431 & 87.456 & 61.270 & 76.942 & 55.020 \\
\hline Hunan & 68.304 & 54.029 & 68.592 & 55.196 & 58.679 & 40.080 \\
\hline Yunnan & 52.612 & 67.435 & 80.592 & 57.064 & 67.680 & 35.608 \\
\hline Liaoning & 69.591 & 37.521 & 62.085 & 53.935 & 50.668 & 35.261 \\
\hline Hainan & 46.128 & 64.144 & 77.260 & 60.402 & 66.596 & 30.720 \\
\hline Jiangxi & 44.897 & 59.169 & 80.948 & 56.134 & 64.763 & 29.076 \\
\hline Guangxi & 41.824 & 65.352 & 84.020 & 57.708 & 68.336 & 28.581 \\
\hline Sichuan & 49.319 & 57.957 & 62.878 & 51.392 & 56.835 & 28.030 \\
\hline Hubei & 47.241 & 48.774 & 74.636 & 55.842 & 59.153 & 27.944 \\
\hline Heilongjiang & 46.628 & 44.702 & 76.709 & 51.345 & 57.010 & 26.583 \\
\hline Gansu & 37.496 & 74.693 & 73.497 & 57.830 & 67.987 & 25.493 \\
\hline Henan & 37.573 & 55.256 & 70.003 & 56.746 & 60.062 & 22.567 \\
\hline Zhejiang & 42.439 & 33.435 & 61.306 & 53.898 & 49.051 & 20.817 \\
\hline Chongqing & 31.415 & 58.064 & 83.036 & 55.298 & 64.812 & 20.360 \\
\hline Shaanxi & 34.291 & 54.300 & 66.461 & 58.408 & 59.126 & 20.275 \\
\hline Jilin & 35.782 & 42.762 & 76.034 & 51.606 & 56.233 & 20.121 \\
\hline Inner Mongolia & 34.270 & 47.946 & 66.628 & 53.436 & 55.443 & 19.000 \\
\hline Anhui & 23.295 & 57.729 & 84.574 & 59.171 & 66.487 & 15.488 \\
\hline Shanxi & 26.320 & 57.451 & 61.319 & 58.065 & 58.356 & 15.359 \\
\hline Xinjiang & 25.072 & 57.560 & 63.724 & 54.169 & 57.900 & 14.517 \\
\hline Hebei & 26.186 & 49.110 & 60.519 & 57.837 & 55.264 & 14.471 \\
\hline Shandong & 25.223 & 31.983 & 61.090 & 57.895 & 49.819 & 12.566 \\
\hline Guangdong & 21.985 & 44.033 & 60.650 & 55.989 & 53.022 & 11.657 \\
\hline Ningxia & 15.057 & 60.136 & 75.688 & 56.098 & 63.334 & 9.536 \\
\hline Fujian & 13.000 & 43.001 & 78.000 & 57.283 & 58.834 & 7.648 \\
\hline Jiangsu & 13.311 & 34.446 & 70.685 & 56.025 & 53.181 & 7.079 \\
\hline Tibet & 10.496 & 59.717 & 73.165 & 54.134 & 61.715 & 6.478 \\
\hline Qinghai & 7.840 & 59.749 & 81.212 & 57.475 & 65.484 & 5.134 \\
\hline Beijing & 0.860 & 14.486 & 20.948 & 45.813 & 26.811 & 0.230 \\
\hline Tianjin & 0.023 & 21.182 & 67.034 & 48.088 & 44.980 & 0.010 \\
\hline Shanghai & 0.015 & 18.962 & 50.324 & 50.208 & 39.433 & 0.006 \\
\hline
\end{tabular}




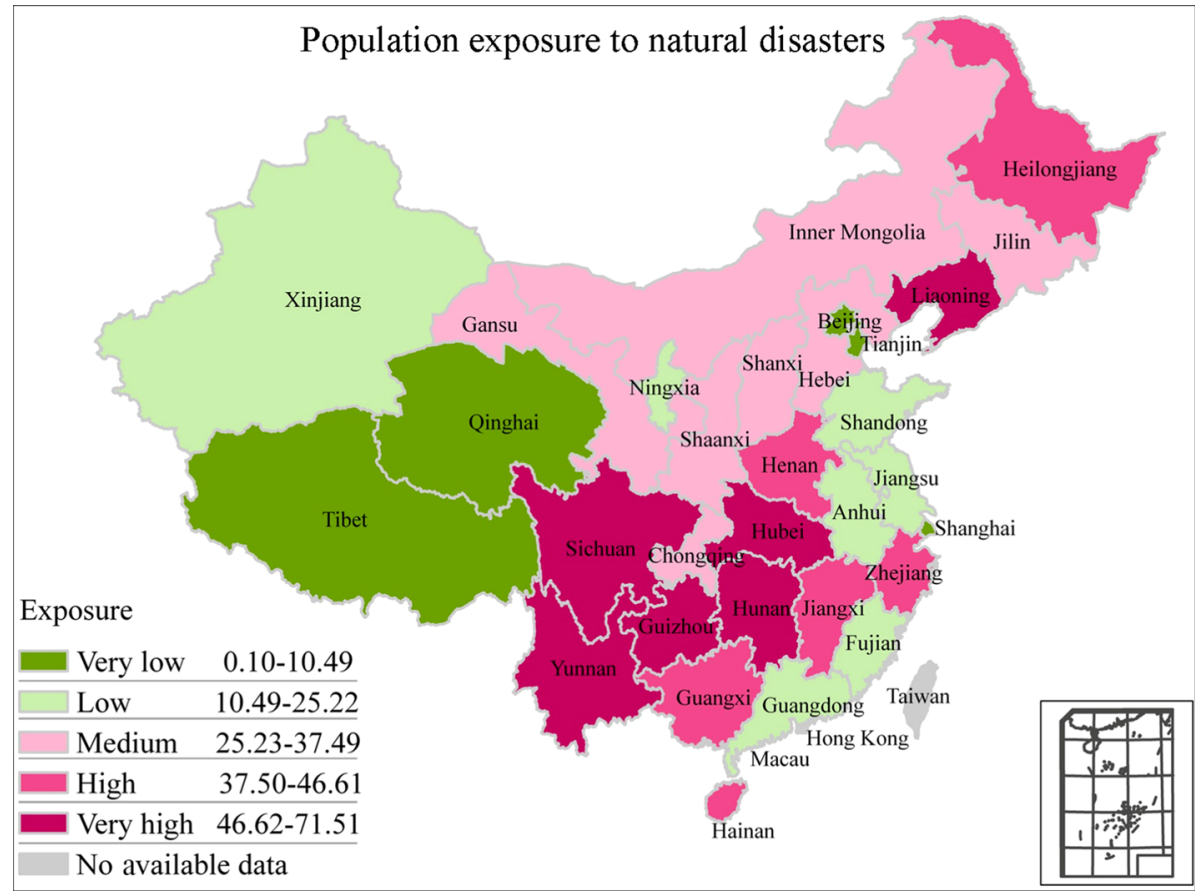

Fig. 4 Annual population exposure to the earthquakes, floods, droughts, low temperatures/snow and gale/ hail in 31 provinces of China during the period of 2008-2010

It is generally accepted that the eastern area of China belongs to the well-developed region, and the western and central regions are the less-developed region.

\section{Results and analysis}

\subsection{Exposure to natural hazards}

Indices of exposure, susceptibility, coping capacity and adaptive capacity, and vulnerability and risk for 31 provinces in China are shown in Table 2. The map of exposure to natural hazards indicates that Guizhou, Liaoning, Hunan, Yunnan, Sichuan and Hubei provinces were the exposure hotspots, followed by Heilongjiang, Hainan, Jiangxi, Zhejiang, Guangxi and Henan (Fig. 4). Southwestern China, including Guizhou, Yunnan and Sichuan provinces, was highly exposed to frequent floods, droughts, low temperatures/ snow and gale/hail. Devastating earthquakes also exposed a larger number of people to hazards in Sichuan and Yunnan provinces, whose geographical locations are near tectonic plate borders. The elevation of China is higher in the west and lower in the east; thus, coupled with the southeast and southwest monsoonal influences, the Yangtze River region experienced floods every year. A larger number of people were exposed to frequent floods and low temperatures/snow in the central regions of China (including Hunan, Hubei and Jiangxi provinces). In addition, many people were exposed to droughts and gale/hail in Hunan and Hubei provinces every year. Due to the effects of droughts and floods, 

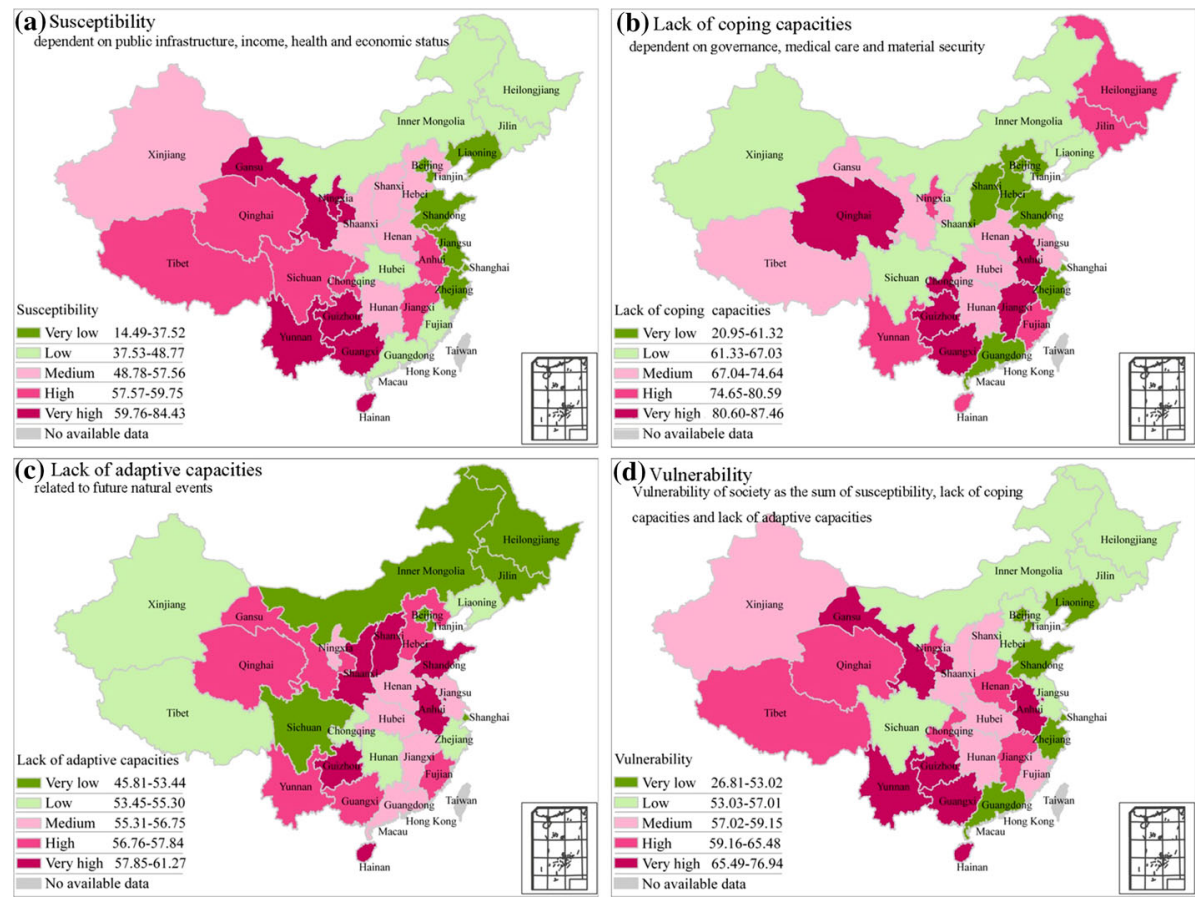

Fig. 5 Classification of susceptibility (a), lack of coping capacity (b), lack of adaptive capacity (c) and vulnerability (d) for different provinces in China (the classification is based on the quantile method; the max value for six elements $a-f$ was $100 \%$ )

Northeast China (including Liaoning and Heilongjiang provinces) also had a high population exposure. According to the government statistics, Beijing, Tianjin and Shanghai had a relatively lower frequency of natural hazards between 2008 and 2010, and few people were affected by disasters in these regions (i.e., low exposure) (Fig. 4).

\subsection{Susceptibility, coping capacity, adaptive capacity and vulnerability to natural hazards}

The southwestern and western regions of China had a relatively high level of susceptibility, while the economically well-developed areas, such as Beijing, Tianjin, Shanghai and Shandong, and the northwestern region (including Liaoning, Jilin and Heilongjiang) had a relatively low level of susceptibility (Fig. 5a). The results indicate that the level of economic development could be closely associated with the susceptibility to natural hazards. The most susceptible provinces, such as Guizhou, Gansu, Yunnan and Guangxi, have a higher proportion of households with difficult access to drinking water, a greater dependency ratio, higher poverty incidence and larger differences in income distributions (Fig. 6a). A greater dependency ratio and higher Gini-index may be the main reasons for the higher susceptibility in Ningxia, Qinghai, Tibet, Jiangxi, Chongqing and Sichuan provinces. In contrast, the least sensitive regions, e.g., Beijing, Tianjin and Shanghai, have better health, fewer households with difficult access to drinking water, lower dependency 


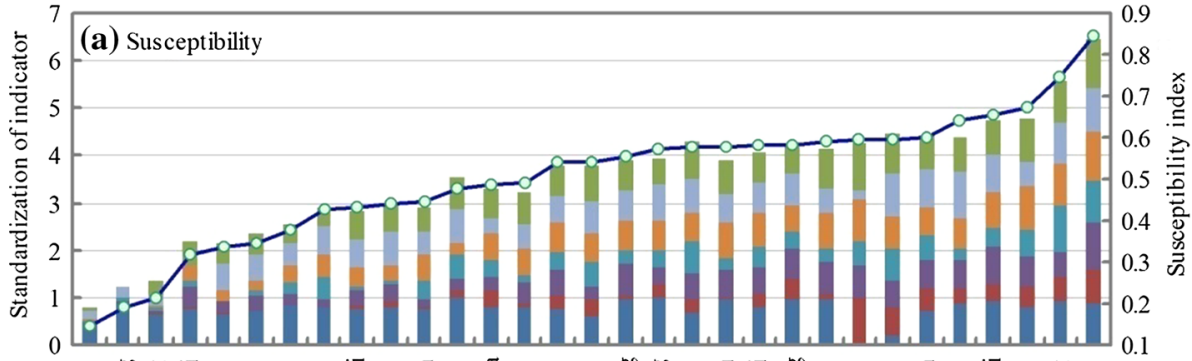

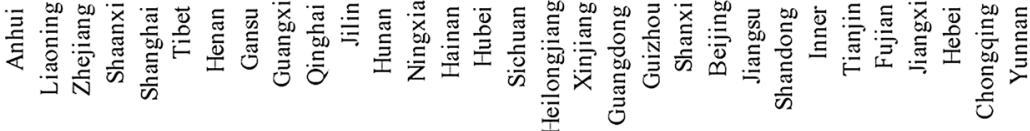

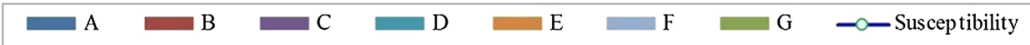

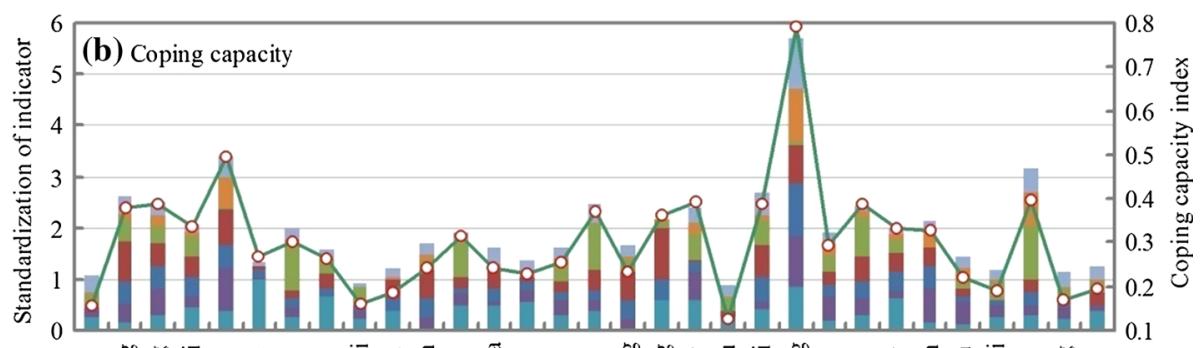

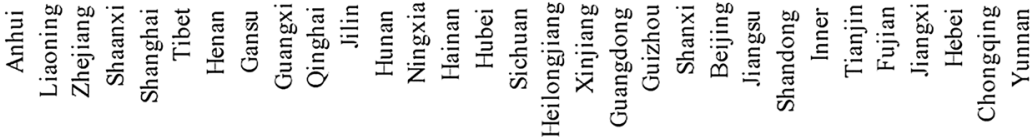

$=\mathrm{H} \rightleftharpoons \mathrm{I} \rightleftharpoons \mathrm{J} \rightleftharpoons \mathrm{K} \rightleftharpoons \mathrm{L} \rightleftharpoons \mathrm{M} \rightleftharpoons \mathrm{N} \rightleftharpoons$ Coping capacity

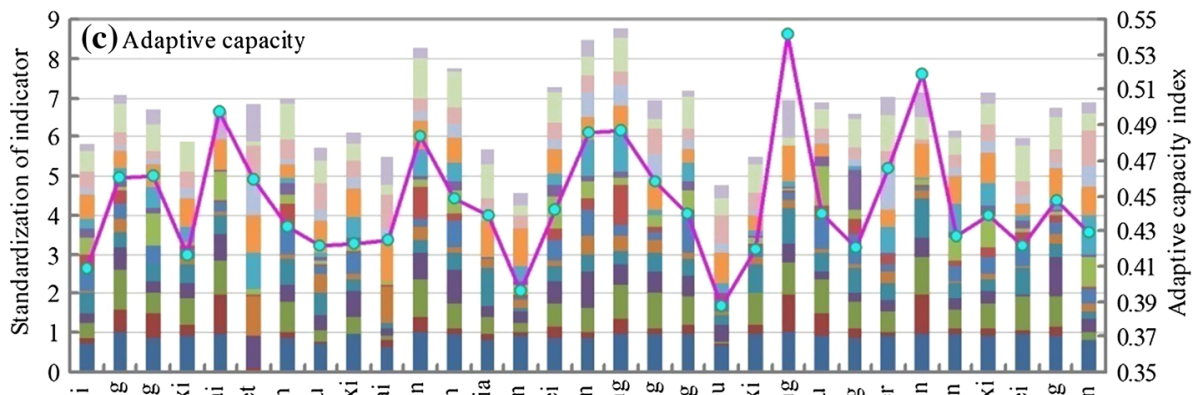

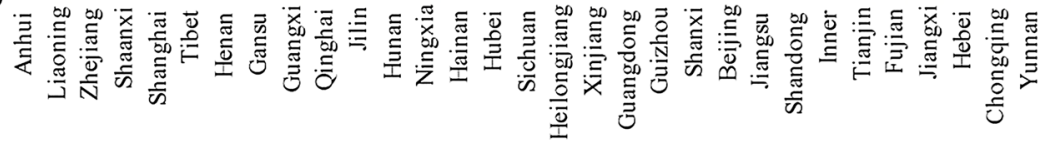

\begin{tabular}{|c|c|c|c|}
\hline $\begin{array}{c}\mathrm{O} \\
\mathrm{S} \\
\mathrm{U} 3 \\
\mathrm{~W} 2 \\
- \text { - Adaptive capacity }\end{array}$ & $\begin{array}{l}\mathrm{P} \\
\mathrm{T} \\
\mathrm{U} 4 \\
\mathrm{X}\end{array}$ & $\begin{array}{l}\text { Q } \\
\text { U1 } \\
\text { V } \\
\text { Y }\end{array}$ & $\begin{array}{l}\mathrm{R} \\
\mathrm{U} 2 \\
\mathrm{~W} 1 \\
\mathrm{Z}\end{array}$ \\
\hline
\end{tabular}


4Fig. 6 Indices for susceptibility (a), coping capacity (b) and adaptive capacity (c) for different provinces (Note the horizontal axis represents China's 31 provinces and the vertical axis represents the normalized values of the indicators of susceptibility, coping capacity and adaptive capacity; the letters $A-G$ represent the indicators of susceptibility, $H-N$ represent coping capacity, and $O-Z$ represent adaptability. The meanings of the indicators $A-Z$ are same as in Table 1)

ratios, smaller populations in extreme poverty and higher levels of economic development (Fig. 6a).

Guizhou, Anhui, Guangxi, Chongqing, Qinghai and Jiangxi had the greatest lack of coping capacity for natural hazard events, followed by Yunnan, Fujian, Hainan, Heilongjiang, Jilin and Ningxia (Fig. 5b). Poorer medical services (the number of beds, physicians and health institutions), inefficient governments and authorities (high corruption perceptions index and low comprehensive development index) and lower economic coverage (insurance density and penetration) in Guizhou, Anhui, Guangxi, Chongqing, Qinghai and Jiangxi provinces were closely correlated with their low capacity to respond to shocks (Fig. 6b). For example, the combination of fewer medical services per 10,000 people, the lower level of comprehensive development and inferior insurance was one of the possible reasons why Guizhou Province had the lowest coping capacity (Fig. 6b). Very few people in Guizhou Province have the opportunity to benefit from well-developed health care in the event of natural hazards. The map of lacking coping capacity also showed that the provinces with the highest coping capacities for a disaster were Beijing, Shanghai, Hebei, Guangdong, Shandong and Zhejiang (Fig. 5b). In general, these welldeveloped provinces have better capacities to cope with events, as compared to lessdeveloped regions, because they have well-developed health care, superior insurance and comprehensive development (Fig. 5b).

The map showing the lack of adaptive capacity clearly identified Beijing, Tianjin, Shanghai, Heilongjiang, Sichuan, Jilin and Inner Mongolia as having the highest adaptive capacities, followed by Zhejiang, Liaoning, Tibet and Hunan. These provinces, including Guizhou, Hainan, Anhui, Shaanxi, Shanxi and Shandong, exhibited massive problems in regard to their adaptive capacities (Fig. 5c). Higher levels of education (adult literacy rate and tertiary gross enrollment ratio), higher gender equality in education and larger government health expenditures may be responsible for the high adaptive capacities in Beijing, Tianjin and Shanghai. The higher adaptive capacities in Heilongjiang, Sichuan, Jilin and Inner Mongolia could be explained by superior ecosystem protection (high ecosystem service value and good forest management) and larger private health expenditures (Fig. 6c). The possible driving forces in Guizhou, Anhui and Hainan, which have the lowest adaptive capacity, are the low adult literacy rate and tertiary gross enrollment ratio, the relatively higher gender disparity in education and employment, fewer ecologically protected areas per unit area and a lower ecosystem service value (Fig. 6c). The reason Tibet was the second highest adaptable province could be explained by its superior ecosystem protection (including larger ecologically protected areas, better forest management and lower ecological footprint ${ }^{3}$ ).

Figure 5d shows the components of susceptibility, the lack of coping capacity and the lack of adaptive capacity. An evaluation of the vulnerability reveals that the most vulnerable provinces to natural hazards were mainly concentrated in southwestern China.

\footnotetext{
${ }^{3}$ Ecological footprint is a negative indicator in terms of capacity for adaptation. The higher the value of ecological footprint, the more resource the human required, which results in more serious impacts on ecology and environment. Therefore, the value of ecological footprint was multiplied by a negative one when calculating the adaptive capacity index.
} 
Gansu, Hainan and Anhui were also the most vulnerable provinces. Most of the welldeveloped regions were the least vulnerable, for example Beijing, Shanghai, Tianjin, Zhejiang and Shandong provinces. Two of the most vulnerable provinces, i.e., Anhui and Yunnan, had a high susceptibility to natural events, a low coping capacity and a low adaptive capacity. Guangxi and Hainan provinces also exhibited similar characteristics to Anhui and Yunnan. Guizhou Province was characterized by a very high susceptibility, a very low coping capacity, a very low adaptive capacity and high vulnerability. In contrast, three municipalities (Shanghai, Beijing and Tianjin) had very low susceptibilities and, to an extent, a very high coping capacity and adaptability, which results in a very low level of vulnerability. Among the least vulnerable provinces, Zhejiang had a very low susceptibility, high coping capacity and moderate level of adaptability. Liaoning was characterized by a low susceptibility, moderate level of coping and moderate adaptive capacities. Additionally, although Shandong and Guangdong provinces greatly lacked the capacity to adapt, their lower susceptibility and higher coping capacity levels resulted in a very low vulnerability (Fig. 5d).

\subsection{Chinese disaster risk index (CDRI)}

The CDRI map shows that there were six provinces demonstrating a very high disaster risk, whereas seven had a very low risk level (Fig. 7). Guizhou had the highest disaster risk, followed by Hunan, Yunnan, Liaoning, Hainan and Jiangxi. The seven provinces with the lowest risk levels were Shanghai, Tianjin, Beijing, Qinghai, Tibet, Jiangsu and Fujian. The

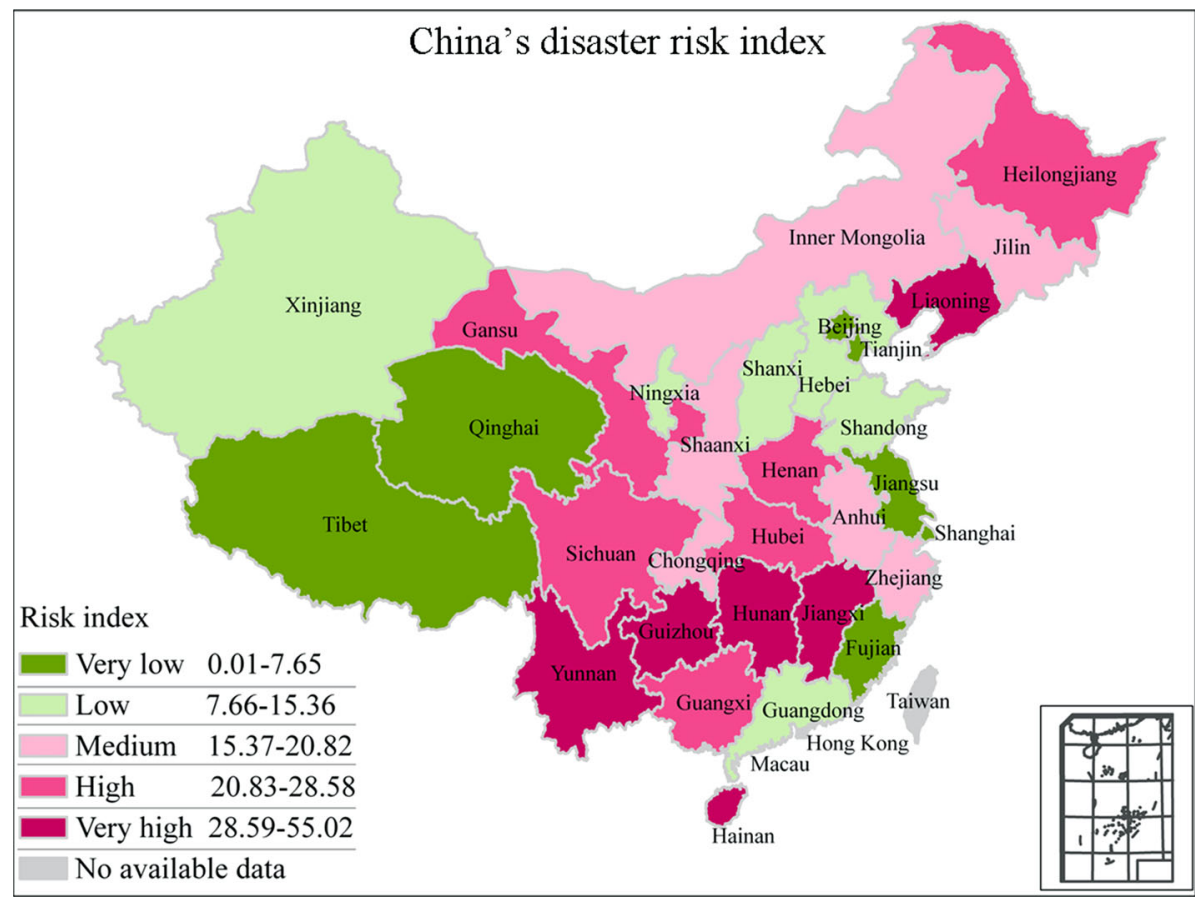

Fig. 7 Relative disaster risk levels for 31 provinces in China 


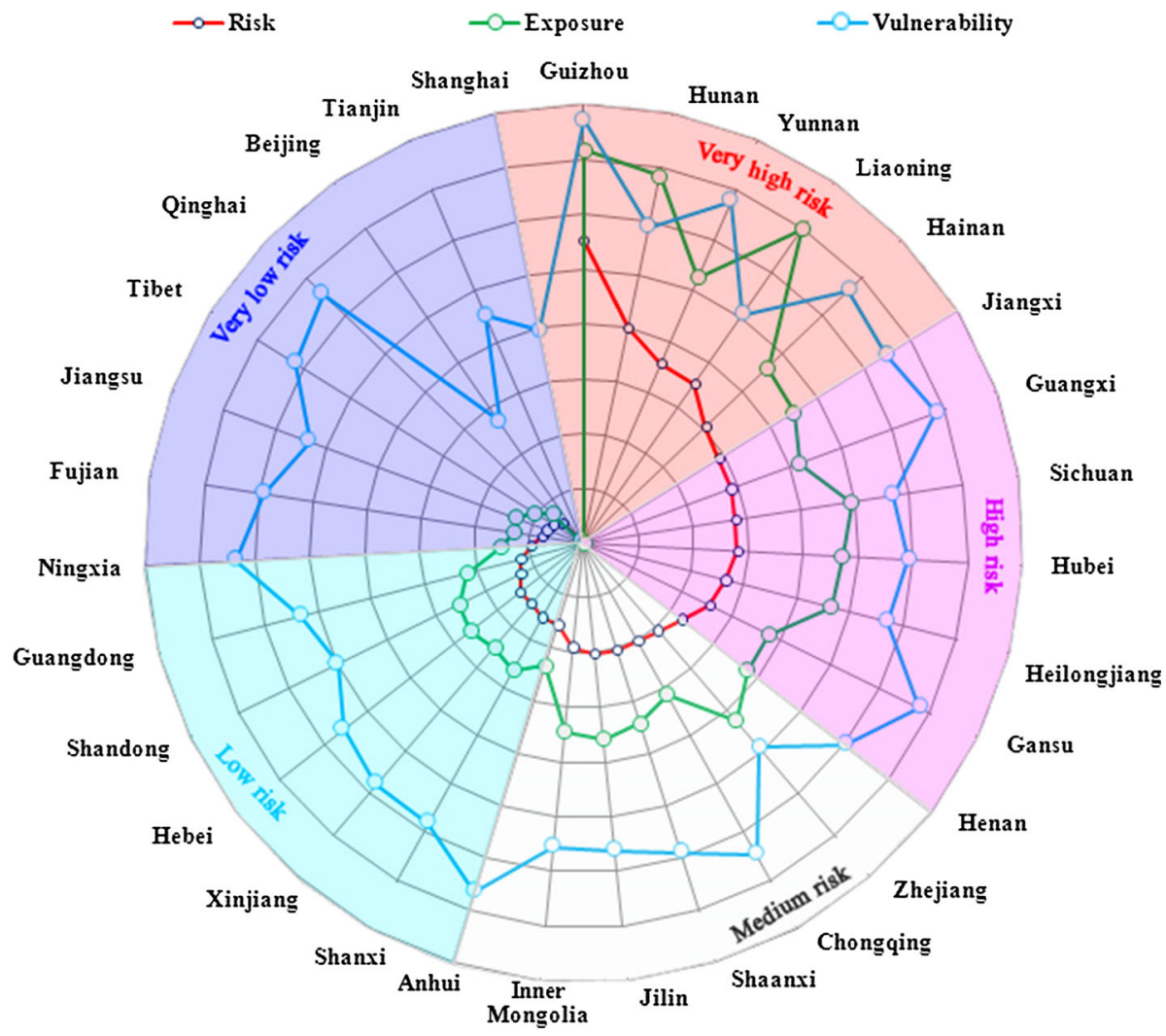

Fig. 8 Exposure, vulnerability and disaster risk for 31 provinces in China

six provinces with moderate disaster risk levels were Zhejiang, Chongqing, Shannxi, Jilin, Inner Mongolia and Anhui.

The CDRI was the product of exposure and vulnerability. Four of the provinces that experienced the greatest risk were also among the top six most exposed provinces. However, the results for Sichuan and Hubei suggested that high population exposure to natural hazards does not necessarily lead to an especially high disaster risk (Fig. 8). Sichuan and Hebei provinces exhibited similarly high exposure values to natural hazards as Yunan; however, when combined with moderate and low levels of vulnerability, the risk value was lower. There were higher education levels (including a higher adult literacy rate and tertiary gross enrollment ratio), higher gender equality in education and employment and more emphasis on biodiversity protection in Sichuan than in Yunnan; thus, the latter province was more vulnerable to natural hazards. The differences in the vulnerability between Sichuan and Yunnan resulted in different levels of disaster risks. Different disaster exposure levels under similar vulnerability also produced distinctly different risk types, such as that found in Yunan, Gansu, Hainan and Anhui provinces. Only the combination of high exposure and high vulnerability led to high risk. As shown for Guizhou and Yunnan provinces, both the high exposure and vulnerability produced an extremely high disaster risk (Fig. 8). These results indicate that a highly vulnerable population was heavily exposed, whereas low vulnerability mitigated the exposure and resulted in a lower risk. 

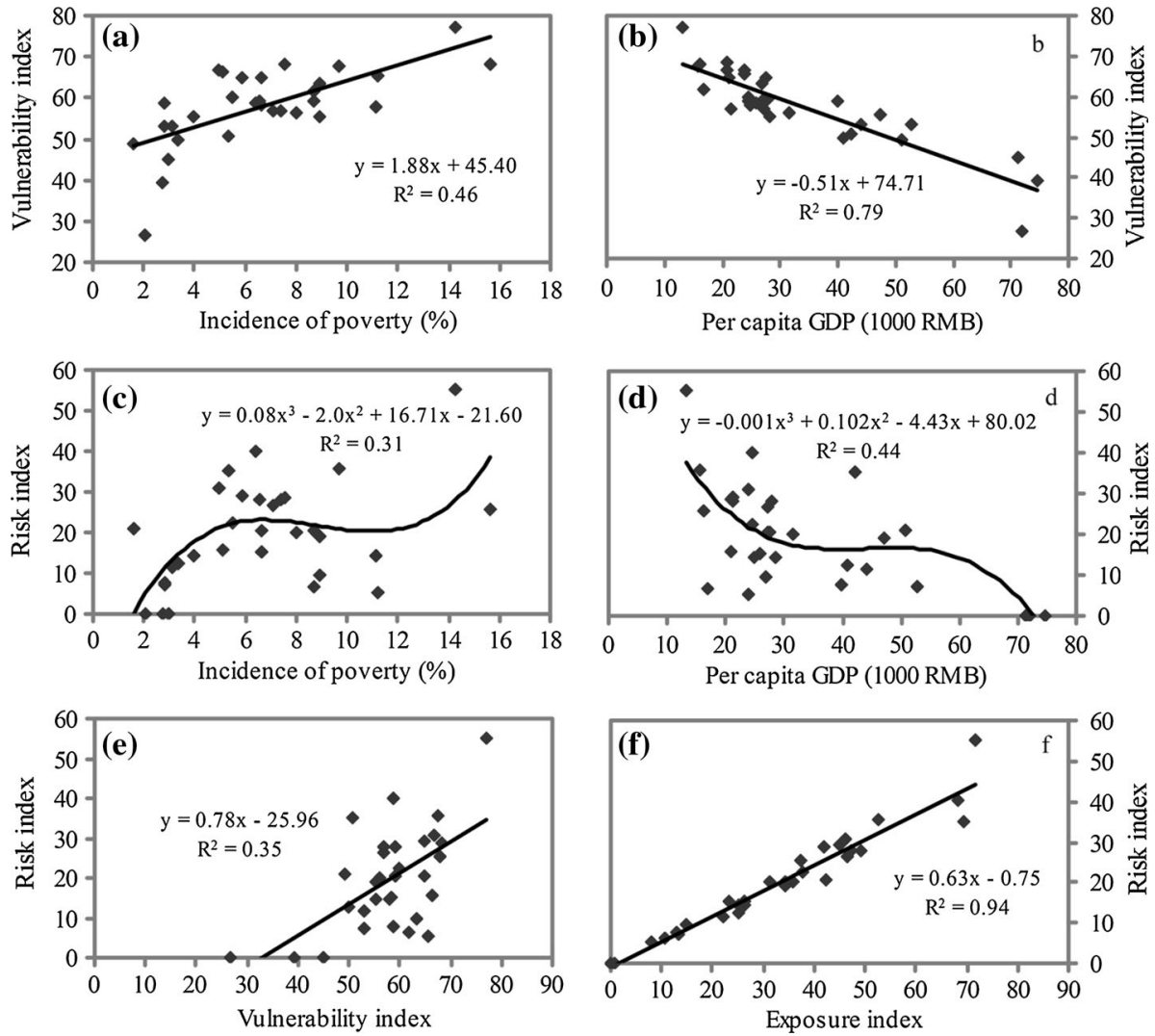

Fig. 9 Relationships between risk and vulnerability, exposure, poverty and per capita GDP

\subsection{Poverty, economic development, exposure, vulnerability and risk}

The relationships between poverty, economic level, exposure, vulnerability and disaster risk have received widespread attention over the past decades. Poverty has been considered an important aspect of vulnerability due to its direct association with access to resources, which affects both baseline vulnerability and coping with the impacts of extreme events (Adger 2006; IPCC 2012). Poverty generally affects vulnerability through individuals' expectations of the impacts of hazards and through their ability to invest in risk alleviation; the limited opportunities for coping and reducing the resilience to impacts directly affect the recovery from extreme events (Adger 2000). Thus, extreme poverty increases the susceptibility to harm.

In China, vulnerability was closely correlated with poverty and per capita GDP (Fig. 9a, b). We observed that China's vulnerability was positively and significantly associated with the incidence of poverty but negatively associated with per capita GDP $(p<0.01)$; thus, some regions with higher poverty incidences and lower economic development levels, such as Yunnan, Guangxi and Guizhou, tend to exhibit relatively higher disaster vulnerability. This result is in agreement with an existing study that shows lower wealth levels increased disaster vulnerability (Kellenberg and Mobark 2007). Figure 9c, d provides information on 
the relationship between disaster risk level and poverty incidence as well as economic development at the provincial scale of China. A nonlinear relationship exists between risk index and poverty incidence as well as per capita GDP; this is consistent with previous studies (Kellenberg and Mobark 2007; Schumacher and Strobl 2008; Zhou et al. 2014b). Provinces with high disaster risk levels were concentrated in middle-income regions. The regions with lower GDP per capita and higher physical exposure, such as Guizhou and Yunnan provinces, were associated with higher levels of risk. These results suggest that less-developed areas would suffer higher levels of mortality and relative economic loss than well-developed areas when disasters occur if economic policies do not account for the rising disaster risk. Economic and population exposure to disasters is increasing at a faster rate than the upward trends in wealth and efforts to adequately protect people and assets (Mitchell et al. 2012). The relationship between disaster risk and per capita GDP as well as poverty in China also suggests that efforts to eliminate poverty and to increase development may be a successful policy implementation for effective disaster risk mitigation. Furthermore, there have less willingness to accept disaster insurance for people from regions with a greater multi-hazard threat, but buying insurance may be also an effective way to reduce disaster risk (Wang et al. 2012c). In addition, the correlations between disaster risk and exposure as well as vulnerability demonstrate that risk was more closely related to exposure $\left(R^{2}=0.94, p<0.01\right)$ than vulnerability $\left(R^{2}=0.35, p<0.01\right)$ at the significance level of 0.01 (Fig. 8e, f). The results further suggest that the physical exposure to hazards played a role in the level of disaster risks, while vulnerability, especially social vulnerability, amplified the adverse effects of natural disasters.

\section{Discussion}

Disaster risk assessment aims to examine the latent factors that cause losses in order to estimate loss probabilities, and it can help inform efforts to intervene to reduce risks and therefore losses before such occur (Dilley et al. 2005). The WRR shifted away from the typical short-term view of disasters and concentrated on a developmental approach; it focused on aspects such as prevention, protection of particularly vulnerability groups and risk management. Linking the social and economic dimensions of risk with the classical hazard analysis of natural events will create a new approach for risk assessments and provide forward-looking conclusions for both decision-makers and practitioners. This study assessed the integrated and relative risks to five major natural disasters at the provincial scale in China within a general theoretical framework provided by the WRR. Although the structure of the provincial risk index corresponds to the structure of the global index, some indicators had to be adapted to the data or discarded due to the limited data. One of the advantages of a provincial risk index is the possibility to account for important aspects that would be relevant to disaster risks at the sub-national level for which no globally comparable data are available. It is therefore feasible and reasonable to integrate the following indicators in the index: comprehensive development index, water resources carrying capacity, terrestrial ecosystem service value and ecological footprint (Table 1; Fig. 2). These indicators were correlated with the ability to adapt to natural hazards as well as the vulnerability of a community or country (Adger et al. 2005; Smit and Wandel 2006; Das and Vincent 2009; Keys et al. 2014). There is growing consensus that the quality of the ecosystem has a significant effect on the ability to cope with and adapt to natural hazards or adverse shocks (Adger 2000, 2006; Adger et al. 2005; Smit and Wandel 
2006). Therefore, our results revealed the provincial differences in disaster risks and identified the possible mechanisms behind these risk-level disparities. The findings further confirmed that geographical areas that have been identified as high risk or hotspots at the global scale have a highly variable spatial distribution of risk at finer scales (Arnold et al. 2006).

However, some uncertainties still exist in this study. First, our work is mainly focused on the relative integrated risk levels of five types of hazards (droughts, earthquakes, floods, low temperatures/snow and gale/hail) rather than specific hazards. The multi-hazard index is obviously strongly influenced by the choice of measurement of the degree or severity of a hazard (Dilley et al. 2005). Furthermore, the present study did not consider the physical exposure to typhoons due to the low incidence of typhoon disasters in China (nine of the 31 provinces experienced a typhoon during 2008-2010). Therefore, the risk evaluation of typhoons was beyond the scope of this study. A different disaster risk pattern would have been produced for China's coastal areas if we had considered the impacts of typhoons on humans. Second, some important factors in measuring susceptibility, coping capacity and adaptive capacity and in measuring vulnerability to natural hazards, such as housing conditions, disaster preparedness, early warnings, social networks and institutional dimensions, were not considered in the CDRI. Built-environmental factors amplify or attenuate the adverse effects of natural hazards (Borden et al. 2007). Different types of buildings would resist to the impact of disaster events differently, resulting in different damage levels even under the same intensity (Tsao et al. 2010; Lo et al. 2012). Robust early warning systems play a critical role in reducing the impacts of potential disasters and enable populations to protect lives, property and infrastructure (Adger et al. 2007; Rogers and Tsirkunov 2010; IPCC 2012). Social networks facilitate the transmission of information about risk, and communities with stronger social networks appear to be better prepared for disaster impacts (IPCC 2012). Institutional factors (such as lack of policies, spatial panning practices, knowledge, training, discussion, implementation tools) play a critical role in adaptation as they influence the social distribution of vulnerability and shape adaptation capacities (Adger 2000; Næss et al. 2005). However, to date, no sufficient information on these aspects is available at the provincial level in China. Finally, this study was only concerned with the population exposure to natural hazards, and it failed to consider property exposure because the accuracy of the population exposure data is usually higher than that of property loss data; additionally, the recorded information of the former is more complete than the latter. The potential exposure of land, population and other features of each province varies greatly across space and time; thus, the overall risk considered in a multi-hazard index will be influenced by a range of highly uncertain factors. We hope that disaster-related mortality and loss risks will be included in China's disaster risk assessment model in the future.

Disaster risks cannot fully be eliminated because natural hazards are beyond our control, but its impacts can be mitigated. Exposure is a physical contribution to disaster risk, whereas vulnerability is a human-based contribution to risk (IPCC 2012). The levels of adverse effects of disasters are largely determined by the vulnerability and exposure of societies and social-ecological systems (UNISDR 2009; Cardona 2011). Over the next few decades, population growth, urbanization and economic growth will continue to increase the exposure to natural perils in many regions. Disaster risks continue to grow as rapid urbanization increases as a result of the drive for economic growth and social improvement. Therefore, vulnerability reduction is a core element of managing or reducing disaster risk. Understanding vulnerability is a prerequisite for understanding risk and developing risk reduction and adaptation strategies for disaster events (UNISDR 2011). Measures 
could be taken to reduce vulnerability, e.g., poverty reduction, health improvements, livelihood diversification, access to decision-making and community security improvements (IPCC 2012). In China's high-risk regions, such as Guizhou and Yunnan provinces, poverty reduction, improvements in critical infrastructure and medical services, and increases in political transparency would help to reduce vulnerability among exposed populations to natural hazards. More specifically, in Guizhou, the combination of increasing the accessibility of households to drinking water, reducing the dependency ratio through reasonable population policies and narrowing the income gap would help to reduce the regions susceptibility and mitigate disaster risk. In Hainan and Jiangxi, vulnerability reduction could be achieved by improving the level of education and medical services and emphasizing the role of insurance in risk sharing and transfers. The goals of disaster risk mitigation could be accomplished by considering the mainstream risk management in the development process, developing a reasonable land use planning policy and implementing incentives to move individuals away from disaster-prone areas to reduce exposure (Turner et al. 2003).

\section{Conclusions}

The present disaster data in China are inadequate for understanding the absolute levels of risk posed by any specific hazard or combination of hazards, but they are adequate for identifying regions that have relatively higher multi-hazard risks. This study identified Guizhou, Hunan, Yunnan, Liaoning, Hainan and Jiangxi provinces as high-risk regions of multiple hazards and Shanghai, Tianjin, Beijing, Qinghai, Tibet, Jiangsu and Fujian as lowrisk areas. Notably, among the six provinces with the highest risk, four had a high population exposure to hazards. Very high exposure is a significant risk driver in China, although a relatively higher development level can reduce vulnerability, as Liaoning Province reveals. Because it had the highest population exposure, highest susceptibility to natural hazards, poorest coping capacity and poorest adaptive capacity, Guizhou Province had the largest disaster risk in China. Similar to the population exposure to disasters, the relative risk levels in the southwestern, central and northeastern regions of China were significantly higher than those in the eastern, northern and western areas.

China's disaster risk analysis has important implications for the development of investment planning, disaster preparedness and loss prevention. The highest risk areas are those where disasters are expected to occur most frequently and losses are projected to be the highest. This provides a rational basis for prioritizing risk reduction efforts and highlights areas where risk management is most needed. Reducing exposure and vulnerability would provide opportunities for at-risk populations to lower the adverse effects of a disaster. Poverty reduction, improvements in critical infrastructure and medical services, and increases in political transparency can help the provinces with high risks to reduce susceptibility and improve the ability to respond and adapt to natural hazards. Further, reasonable land use planning and advancement of risk awareness could help reduce the population exposed to disasters. Our findings could provide a scientific basis for guiding effective disaster risk management in the future.

Acknowledgments This research was supported by the National Basic Research Program of China (973 Program) (2012CB955402) and National Natural Science Foundation of China (41130748). The authors would like to acknowledge anonymous reviewers for their useful comments which have greatly improved the manuscript. 


\section{References}

Adger WN (2000) Social and ecological resilience: Are they related? Prog Hum Geogr 24(3):347-364

Adger WN (2006) Vulnerability. Glob Environ Change 16(3):268-281

Adger WN, Hughes TP, Folke C, Carpenter SR, Rckstrom J (2005) Social-ecological resilience to coastal disasters. Science 309:1036-1039

Adger WN, Agrawala S, Mirza MMQ, Conde C, O’Brien K, Pulhin J, Pulwarty R, Smit B, Takahashi K (2007) In: Parry ML, Canziani OF, Palutikof JP, van der Linden PJ, Hanson CE (eds) Assessment of adaptation practices, options, constraints and capacity. Climate change 2007: impacts, adaptation and vulnerability. Contribution of Working Group II to the Fourth Assessment Report of the Intergovernmental Panel on Climate Change. Cambridge University Press, Cambridge, UK

Alliance Development Works (2012) Environmental degradation and disasters: World Risk Report 2012. Alliance Development Works, Bonn

Arnold M, Chen RS, Deichmann U, Dilley M, Lerner-Lam AL, Pullen RE, Trohanis Z (2006) Natural disasters hotspots case studies. Disaster risk management series no. 6. The World Bank Hazard Management Unit, Washington, DC

Bell R, Glade T (2004) Multi-hazard analysis in natural risk assessments. Risk Anal 9:197-206

Birkmann J (2006) Measuring vulnerability to natural hazards: towards disaster resilient societies. United Nations University Press, Tokyo

Birkmann J (2007) Risk and vulnerability indicators at different scales: applicability, usefulness and policy implications. Environ Hazards 7(1):20-31

Birkmann J (2011) Regulation and coupling of society and nature in the context of natural hazards. In: Brauch HG, Oswald Spring U, Mesjasz C, Grin J, Kameri-Mbote P, Chourou B, Dunay P, Birkmann J (eds) Coping with global environmental change, disasters and security. Springer, Berlin, pp 1103-1127

Birkmann J, Welle T, Krause D, Wolfertz J, Catalina S, Neysa S (2011a) World Risk Index: concept and results. In: World Risk Report 2011. Alliance Development Works, pp 13-42. ISBN 978-3-9814495-1-8

Birkmann J, Cardona OD, Carreno ML, Barbat AH, Barbat AH, Pelling M, Schneiderbauer S, Kienberger S, Keiler M, Alexander D, Zeil P, Welle T (2013) Framing vulnerability, risk and societal response: the MOVE framework. Nat Hazards 67(2):193-211

Borden KA, Schmidtlein MC, Emrich CT, Piegorsch WW, Cutter SL (2007) Vulnerability of US cities to environmental hazards. J Homel Secur 4(2):1-21

Cardona OD (2011) Disaster risk and vulnerability: notions and measurement of human and environmental insecurity. In: Brauch HG, Oswald Spring U, Mesjasz C, Grin J, Kameri-Mbote P, Chourou B, Dunay $\mathrm{P}$, Birkmann J (eds) Coping with global environmental change, disasters and security-threats, challenges, vulnerabilities and risks. Springer, Berlin, pp 107-122

Cutter SL, Finch C (2008) Temporal and spatial changes in social vulnerability to natural hazards. Proc Natl Acad Sci USA 105(7):2301-2306

Das S, Vincent J (2009) Mangroves protected villages and reduced death toll during Indian super cyclone. Proc Natl Acad Sci USA 106(18):7357-7360

Dilley M, Chen RS, Deichmann U, Lerner-Lam AL, Arnold M, Agwe J, Buys P, Kjekstad O, Lyon B, Yetman G (2005) Natural disaster hotspots: a global risk analysis, Synthesis Report. Center for Hazards \& Risk Research at Columbia University

Dong B, Torgler B (2013) Causes of corruption: evidence from China. China Econ Rev 26:152-169

Fuchs S, Keiler M, Sokratov SA (2013) Spatiotemporal dynamics: the need for an innovative approach in mountain hazard risk management. Nat Hazards 68(3):1217-1241

Gao JM, Zhang W, Yang J (2011) Study on Shaanxi provincial total expenditure on health's financing level and proportion. Chin Health Econ 30(5):19-21

Ge L, Xie G, Zhang C, Li S, Qi Y, Cao S, He T (2011) An evaluation of China's water footprint. Water Resour Manag 25:2633-2647

IPCC (2012) Managing the risks of extreme events and disasters to advance climate change adaptation. A Special Report of Working Groups I and II of the Intergovernmental Panel on Climate Change. Cambridge University Press, New York

Kaiser W (1974) The spectral sensitivity of the honeybee's optomotor walking response. J Comp Physiol A 90(4):405-408

Kappes M, Keiler M, von Elverfeldt K, Glade T (2012) Challenges of analyzing multi-hazard risk: a review. Nat Hazards 64(2):1925-1958

Kellenberg D, Mobark A (2007) Does rising income increase or decrease damage risk from natural disasters? J Urban Econ 63(3):788-802

Keys N, Bussey M, Thomsen DC, Lynam T, Simth TF (2014) Building adaptive capacity in South East Queensland, Australia. Reg Environ Change 14:501-512 
Lerner-Lam A (2007) Assessing global exposure to natural hazards: progress and future trends. Environ Hazards 7(1):10-19

Li KM (2011) Yearbook of China's Insurance 2007-2011. China Insurance Yearbook Press, Beijing

Linnerooth-Bayer J, Amendola A, Okada N, Shi P (2007) Disaster risk management: pro-active financing to reduce vulnerability. Environ Hazards 7(1):1-6

Liu J, Dong S, Mao Q (2012) Comprehensive evaluation of the water resources carrying capacity for China. Geogr Nat Resour 33(1):92-99

Liu CP, Zeng Y, Huang X, Zhou H, Wu L, Li GG (2013) Financing level and structure of total health expenditure in Hainan province. Chin Health Econ 32(2):54-56 (in Chinese)

Lo WC, Tsao TC, Hus CH (2012) Building vulnerability to debris flows in Taiwan: a preliminary study. Nat Hazards 64(3):2107-2128

Ministry of Civil Affairs of China (MCAC) (2012) China civil affairs' statistical yearbook 1981-2012. China Statistics Press, Beijing (in Chinese)

Ministry of Education of China (MEC) (2011) Educational development statistics bulletin for 31 provinces, municipalities and autonomous regions 2011. (http://www.moe.gov.cn) (in Chinese)

Ministry of Health of China (MHC) (2011) China health statistics yearbook. China Union Medical University Press, Beijing (in Chinese)

Mitchell T, Mechler R, Harris K (2012) Tackling exposure: placing disaster risk management at the heart of national economic and fiscal policy. Climate and Development Knowledge Network, London

Næss L, Bang O, Eriksen S, Vevatne J (2005) Institutional adaptation to climate change: flood responses at the municipal level in Norway. Glob Environ Change 15(2):125-138

National Administration of Surveying, Mapping and Geoinformation (NASMG) (2013) Disaster statistics for 2008-2011, 2013. http://zaiqing.casm.ac.cn. Access date: 20 Aug 2013) (in Chinese)

National Bureau of Statistics of China (NBSC) (2011) China statistical yearbook. China Statistics Press, Beijing (in Chinese)

National Bureau of Statistics Research Institute (NBSRI) (2011) Regional Comprehensive Development Index Report 2010. http://www.stats.gov.cn/tjfx/fxbg/t20111222_402774765.htm (in Chinese)

National Survey Research Center at Renmin University of China (NSRCRUC) (2012) Renmin UniversityChina Development Index (RCDI). http://www.nsrcruc.org/index/rcdi (in Chinese)

Papathoma-Köhle M, Kappes M, Keiler M, Glade T (2011) Physical vulnerability assessment for alpine hazards: state of the art and future needs. Nat Hazards 58(2):645-680

Peduzzi P, Dao H, Herold C, Mouton F (2009) Assessing global exposure and vulnerability towards natural hazards: the Disaster Risk Index. Nat Hazard Earth Syst 9(4):1149-1159

Population and Employment Statistics Division of National Bureau of Statistics (PESDNBS) (2011) China population \& employment statistics yearbook 2000-2011. China Statistics Press, Beijing (in Chinese)

Raschky PA (2008) Institutions and the losses from natural disasters. Nat Hazard Earth Syst 8(4):627-634

Rogers D, Tsirkunov V (2010) Costs and benefits of early warning systems. Global assessment report on disaster risk reduction. United Nations International Strategy for Disaster Reduction and World Bank, Geneva, Switzerland and Washington, DC

Rural Socioeconomic Investigation Division of National Bureau of China (RSIDNBC) (2011) China rural statistical yearbook 2006-2011. China Statistics Press, Beijing (in Chinese)

Schmidtlein MC, Deutsch RC, Piegorsch WW, Cutter SL (2008) A sensitivity analysis of the social vulnerability index. Risk Anal 28(4):1099-1114

Schumacher I, Strobl E (2008) Economic development and losses due to natural disasters: the role of risk. Work. Pap. hal-00356286, Dep. Econ., É c. Polytech

Shi P (2011) Atlas of natural disaster risks of China. Science Press, Beijing (in Chinese)

Shi Y, Wang RS, Huang JL (2012) An analysis of the spatial and temporal changes in Chinese terrestrial ecosystem service functions. Chin Sci Bull 57(17):2120-2131

Smit B, Wandel J (2006) Adaptation, adaptive capacity and vulnerability. Glob Environ Change 16(3):282-292

Smit B, Pilifosova O, Burton I, Challenger B, Huq S, Klein RJT, Yohe G, Adger N, Downing T, Harvey E, Kane S, Parry M, Skinner M, Smith J, Wandel J (2001) Adaptation to climate change in the context of sustainable development and equity. In: McCarthy JJ, Canziani OF, Leary NA, Dokken DJ, White KS (eds) Climate change 2001: impacts, adaptation and vulnerability. Contribution of Working Group II to the Third Assessment Report of the Intergovernmental Panel on Climate Change. Cambridge University Press, Cambridge, UK

State Census Office, National Bureau of Statistics of China (SCO) (2011) Tabulation the 2010 population census of the Peoples Republic of China. China Statistics Press, Beijing

State Council Leading Group Office (SCLGO) (2010) China's second national agricultural census data compilation. China Statistics Press, Beijing 
Strunz G, Post J, Zosseder K, Wegscheider S, Muck M, Riedlinger T, Mehl H, Dech S, Birkmann J, Gebert N, Harjono H, Anwar HZ, Sumaryono Khomarudin RM, Muhari A (2011) Tsunami risk assessment in Indonesia. Nat Hazard Earth Syst 11:67-82

Sun C, Chen S, Zhao S (2013) Spatial correlation pattern analysis of water footprint intensity based on ESDA model at provincial scale in China. J Nat Resour 28(4):571-582 (in Chinese)

Supreme People's Procuratorate (SPP) (2010) Procuratorial yearbook of China 1989-2010. Chinese Procuratorate Press, Beijing (in Chinese)

Tian WM (2012) Provincial income Gini coefficient estimates change and trend analysis. Econ Sci 2:48-59

Tsao TC, Hsu WK, Cheng CT, Lo WC, Chen CY, Chang YL, Ju JP (2010) A preliminary study of debris flow risk estimation and management in Taiwan. In: Chen S-C (ed) Internationales Symposion Interpraevent in the Pacific Rim-Taipei. Internationales Forschungsgesellschaft Interpraevent, Klagenfurt, pp 930-939

Turner BL, Kasperson RE, Matson PA, McCarthy JJ, Corell RW, Christensen L, Eckley N, Kasperson JX, Luers A, Martello ML, Polsky C, Schiller A (2003) A framework for vulnerability analysis in sustainability science. Proc Natl Acad Sci USA 100(14):8074-8079

UNESCO-IOC (2009) Hazard awareness and risk mitigation in Integrated Coastal Management (ICAM), IOC Manuals and Guides. UNESCO, Paris

United Nations Development Programme (UNDP) (2004) Reducing disaster risk. A challenge for development. A global report, UNDP, Bureau for Crisis Prevention and Recovery (BRCP), New York. http://www.undp.org/bcpr/disred/rdr.htm

United Nations International Strategy for Disaster Reduction (UNISDR) (2004) Living with risk: a global review of disaster reduction initiatives, vol 1. United Nations, New York

United Nations International Strategy for Disaster Reduction (UNISDR) (2009) Terminology on disaster risk reduction. UNISDR, Geneva, Switzerland

United Nations International Strategy for Disaster Reduction (UNISDR) (2011) Global assessment report on disaster risk reduction: revealing risk, redefining development. Geneva, pp 178. www.preventionweb. net/gar

Wang YX, Mu YY (2009) The practice and adjustment of China's agricultural subsidies since entered WTO. Chin Agric Sci Bull 25(6):278-284

Wang J, Shi P, Zhu J (1994) A research on regional distribution of major natural hazards in China. J Geogr Sci 49(1):19-26

Wang J, Shi P, Wang P, Wang Y (2006) Spatio-temporal pattern of natural disasters in China. Science Press, Beijing (in Chinese)

Wang LN, Jin CL, Li F, Lin H (2012a) Analysis on the provider distribution of Shanghai total expenditure on health. Chin Health Econ 31(11):11-14 (in Chinese)

Wang M, Song Y, Liu J, Wang J (2012b) Exploring the anthropogenic driving forces of China's provincial environmental impacts. Int J Sustain Dev World 19(5):442-450

Wang M, Liao C, Yang S, Zhao W, Liu M, Shi P (2012c) Are people willing to buy natural disaster insurance in China? Risk awareness, insurance acceptance, and willingness to pay. Risk Anal 32(10): 1717-1740

Wisner B, Blaikie P, Cannon T (2004) At risk: natural hazards, people's vulnerability and disasters, 2nd edn. Routledge, London

Xiao LH, Lei HC (2012) Approach on rapid calculation of provincial total health expenditure and its application. Chin Health Econ 31(5):14-19 (in Chinese)

Zhou Y, Li N, Wu W, Wu J, Gu X, Ji Z (2013) Exploring the characteristics of major natural disasters in China and their impacts during the past decades. Nat Hazards 69(1):829-843

Zhou Y, Li N, Wu W, Shi P (2014a) Local spatial and temporal factors influencing population and societal vulnerability to natural disasters. Risk Anal 34(4):614-639

Zhou Y, Li N, Wu W, Liu H, Wang L, Liu G, Wu J (2014b) Socioeconomic development and the impact of natural disasters: some empirical evidences from China. Nat Hazards 74:541-554 